\title{
The Effectiveness of Saskatoon's
}

\author{
Bicycle Boulevard
}

Daniel Surkan*

\begin{abstract}
Saskatoon, like many cities, is attempting to diversify the transportation options available to its citizens and take advantage of the benefits that urban cycling provides, through an increased investment in bicycle infrastructure. The recent development of a bicycle boulevard, a street that gives priority to cyclists over motor traffic, is an example of Saskatoon's shift. This study examines the effectiveness of Saskatoon's bicycle boulevard by taking an inventory of bicycle infrastructure on this route, measuring demographic information of boulevard users, performing traffic counts, and conducting intercept surveys of boulevard users. This data was analyzed through the lens of National Association of City Transportation Officials (NACTO) boulevard design standards. The data gathered from these methods indicates that Saskatoon's boulevard is successful in some areas and needs improvement in others. While the boulevard appears to successfully address design considerations relating to signage, pavement markings, route planning, and traffic speeds, the City has been less successful in managing traffic volumes and dealing with areas where cyclists must compete with motorists for road space. This study recommends that Saskatoon install motorist volume control measures at key areas of perceived danger throughout the boulevard, to increase its effectiveness. Repaving the street and tackling perceptions of crime in the area are additional recommendations based on the findings of this study.
\end{abstract}

Keywords: bicycle boulevard, active transportation, City of Saskatoon, NACTO, urban transportation, urban planning

\section{Introduction}

On September 7, 2013, a cyclist was wounded in a hit-andrun at the intersection of Avenue $U$ and $23^{\text {rd }}$ Street on Saskatoon's newly completed bicycle boulevard (Hamilton, 2013). The cyclist would later succumb to his injuries. The death of a cyclist on a piece of infrastructure supposedly designed to make cycling safer and more convenient raises concerns regarding the effectiveness of Saskatoon's bicycle boulevard. Data gathering for this study began twelve days after the fatal hit-and-run.

This purpose of this study is to gain an understanding of how well Saskatoon's new bicycle boulevard is serving its cyclist users. Saskatoon is currently adapting its transportation network with an increased focus on active transportation. Examining this key piece of infrastructure is important for determining if Saskatoon is effectively diversifying its citizens' transportation options. The bicycle boulevard is a taxpayer funded development, so this study

\footnotetext{
*Department of Regional and Urban Planning, College of Arts and Science, University of Saskatchewan, Saskatoon, SK, Canada
}

Correspondence: d.surkan@usask.ca 
is important to making sure that public money is spent in such a way that maximizes benefits for Saskatonians.

The ultimate objective of this study is to develop a list of recommendations to improve the bicycle boulevard's effectiveness. These recommendations are based on research involving the users of the boulevard, as well as on comparisons of Saskatoon's bicycle boulevard with accepted standards of boulevard design (National Association of City Transporation Officals [NACTO], 2012). This study first takes an inventory of the current cycling infrastructure in place on the bicycle boulevard. Then, demographic indicators and boulevard user perceptions and suggestions for improvement are compared, to indicate where the existing bicycle boulevard infrastructure needs improvement. Results from this study indicate that improvements to the boulevard are needed in the areas of motorized traffic volume control, road maintenance, and the reduction of the number of areas where cars compete with bicycles for space.

This study on Saskatoon's bicycle boulevard begins with a brief review of the current literature regarding urban cycling and bicycle boulevards, including a discussion of the benefits of and need for cycling infrastructure, the demographics of urban cycling, and the boulevard design standards used in this study. The context of Saskatoon's bicycle boulevard is also discussed. Next, the methodology section describes the field site examined in this study, as well as the three data gathering methods used: infrastructure inventory, traffic counts, and cyclist intercept surveys. The research includes an analysis and comparison of results, as well as a discussion of these results, conclusions, and recommendations.

\section{Literature Review}

\section{Urban Cycling and the Need for Bicycle Infrastructure}

Urban cycling is gaining traction in many cities around the world as a viable, beneficial, and often desirable method of transportation. The City of Saskatoon (2002) identifies cycling as a form of transportation that is often the most efficient for both the cyclist and the city. For the cyclist, biking is cheaper per kilometer travelled than owning a private automobile and is often the fastest transportation option for distances less than ten kilometers. For the city, cycling is economically efficient and easily accommodated on existing infrastructure; it requires minimal space per vehicle for both transportation and parking, and is less wearing on infrastructure than the automobile. The efficiency of cycling also provides environmental benefits. Cycling is the form of transportation with the highest energy efficiency and produces virtually no pollution, except in bicycle maintenance and manufacture. Therefore, cycling is ideal for replacing short car trips, which are highly polluting and the least energy efficient form of transportation. City of Saskatoon (2002) thus links an increase in cycling to the mitigation of "ozone depletion, the greenhouse effect, ground-level air pollution, photochemical smog, acid rain and noise pollution" (p. 4).

\section{The Bicycle Boulevard}

One type of bicycle infrastructure is the bicycle boulevard. The National Association of City Transportation Officials [NACTO] provides comprehensive design guidelines for bicycle boulevards. Bicycle boulevards are defined as "streets with low motorized traffic volumes and speeds, designated and designed to give bicycle travel priority" (NACTO, 2012, para. 1). The design elements necessary to create a well-functioning bicycle boulevard can be divided into the following categories: route planning, signs and pavement markings, motor vehicle speed management, motor vehicle volume management, and the treatment of intersections. Bike boulevards have been found to provide numerous benefits to their surrounding areas, including increased cyclist safety, convenience, and improved resident perceptions of home values, quality of life, noise pollution, and air quality (Minikel, 2012; VanZerr, 2009).

\section{Route Planning}

Bicycle boulevards must follow logical and direct routes, with stops occurring only where absolutely necessary. Low-traffic streets offering direct and continuous routes of 2-5 miles $(3.2-8 \mathrm{~km})$, the length of most urban bike trips, are ideal candidates for bicycle boulevards (NACTO, 2012). To ensure a minimum number of stops for cyclists, stop signs should be oriented towards the streets that intersect the boulevard, with cyclists only stopping if the boulevard crosses major arterials. A bicycle boulevard on a residential street adjacent to a major roadway can offer relatively calm traffic, while still maintaining access to commercial destinations.

\section{Signs and Pavement Markings}

Signs and markings are necessary for verifying that cyclists have priority along the boulevard. Signs and markings that should be considered on a boulevard include modified street signs, painted pavement markings, and way-finding signs. These elements help ensure that cyclists stay on the designated route, raise awareness of the boulevard, brand the boulevard, and direct users to certain destinations (NACTO, 2012). 


\section{Motor Vehicle Speed Management}

Reducing the speed of motor traffic is crucial to diminishing the severity of crashes, reducing the number of cars that pass bikes, enhancing drivers' capabilities to interact with cyclists, reinforcing the priority of cyclists, and creating a comfortable cycling environment. NACTO (2012) recommends that $85 \%$ of motor traffic on a bicycle boulevard should travel at 40 kilometers per hour or less. If motor traffic travels above this speed, then traffic calming methods (see Table 1) may have to be adopted. The ideal speed can be achieved by using reduced speed limits, vertical deflection methods (infrastructure in the form of speed bumps and other similar vertical elements), or horizontal deflection methods (infrastructure such as traffic circles, curb extensions, chokers, and street narrowing).

\section{Motor Vehicle Volume Management}

Managing the volume of motorists that use a bicycle boulevard is necessary to preventing motorists from taking advantage of benefits that are supposed to help cyclists. If no volume control exists, then motorists may use the bicycle boulevard as a short cut with minimal stop signs. An ideal bicycle boulevard should have motor vehicle volumes under 1500 vehicles per day. When volumes are greater than this number, there are many traffic calming methods (see Table 1) that can be applied to discourage car traffic from using the boulevard. These include forced turns and full or partial closures for motor vehicles (NACTO, 2012). In both of these strategies, bike travel can continue unhindered along the bicycle boulevard while motor vehicles cannot. It should be noted that a bicycle boulevard does not aim to remove all motor vehicle traffic. Instead, the boulevard aims to prevent widespread motor vehicle through-traffic while still allowing local traffic. Controlling vehicle volumes improves cyclist comfort and safety and reinforces bicycle priority along the boulevard (NACTO, 2012).

\section{Treatment of Intersections}

A bicycle boulevard should avoid inconvenient complete stops for cyclists wherever possible. At major intersections, signs should warn approaching motorists that they are about to cross a bicycle boulevard. Curb extensions and medians can be used to shorten the distance that bicycles must be exposed to cross-traffic. These features help create a safe and comfortable bicycle-oriented environment (NACTO, 2012).

Offset intersections occur when the bicycle boulevard aligns asymmetrically with an intersecting roadway (NACTO, 2012). Because boulevards are often on residential side streets, this is a common occurrence. Appropriate signage on intersecting streets, bicycle turning lanes, bike lanes, and refuge-providing medians/islands are some methods that can be employed to make these intersections safer.

Table 1: Effectiveness of Selected Traffic Calming Measures

\begin{tabular}{|c|c|c|c|}
\hline Traffic Calming Method & $\begin{array}{l}\text { Average Effect on } \\
\text { Automobile Speed }\end{array}$ & $\begin{array}{c}\text { Average Effect } \\
\text { on Automobile } \\
\text { Volume }\end{array}$ & Description \\
\hline Traffic Circle & $11 \%$ decrease & None & $\begin{array}{l}\text { A raised island, placed in an intersection, } \\
\text { around which traffic circulates. This is a } \\
\text { type of horizontal deflection in speed } \\
\text { control. }\end{array}$ \\
\hline Street Narrowing & $7 \%$ decrease & None & $\begin{array}{l}\text { Street narrowing in the form of curb } \\
\text { extensions and other methods provide } \\
\text { horizontal deflection for speed control at } \\
\text { intersections. }\end{array}$ \\
\hline Choker & $14 \%$ decrease & $20 \%$ decrease & $\begin{array}{l}\text { Involves a mid-block street narrowing } \\
\text { that reduces vehicle traffic to one lane } \\
\text { thus allowing car traffic in only one } \\
\text { direction at a time. Can be designed to } \\
\text { have no effect on bicycle traffic. Effects } \\
\text { motor vehicle speed and volume. }\end{array}$ \\
\hline Full Closure & $\begin{array}{l}\text { Prevents through- } \\
\text { traffic of motor } \\
\text { vehicles }\end{array}$ & $44 \%$ decrease & $\begin{array}{l}\text { Car traffic is not permitted to enter a } \\
\text { portion of a street. Bicycle traffic is not } \\
\text { affected. }\end{array}$ \\
\hline
\end{tabular}

Note: Adapted from Effectiveness - trafficcalming.org, by Fehr \& Peers, retrieved from http://trafficcalming.org Copyright 2013 by Fehr \& Peers 


\section{Demographic Indicators of Bicycle Infrastructure Quality}

Examining who is using bicycle infrastructure can give some indication of the infrastructure's quality. Gender is one such demographic factor, with a higher percentage of women users being associated with higher infrastructure quality. As Emond, Handy, and Tang (2009) point out, there is abundant literature indicating that women are affected by the perceived safety and convenience of cycling infrastructure to a greater degree than men. As exposure to motor traffic increases, female cyclists' comfort levels are found to diminish much faster than their male counterparts', leading to a decrease in female ridership. Areas that invest in high quality bicycle infrastructure, capable of offering protection and convenience, see the proportion of women ridership rise dramatically and sometimes become the majority (Baker, 2009; Emond, Handy, \& Tang, 2009; Orton, 2013). Bicycle boulevards have been identified as the type of cycling infrastructure that provides the most comfort for women, and should therefore have a high proportion of female ridership (Szczepanski, 2013).

Similarly, areas that invest in high-quality infrastructure see more balanced cyclist age-distribution. Countries with well-developed cycling infrastructure, including the Netherlands and Denmark, have much greater bicycle usage across all age groups than the United States (Pucher \& Buehler, 2008). For those aged sixty-five and over, $24 \%$ of local trips are on bicycles in the Netherlands while that same measure is just $0.4 \%$ in the United States (Pucher \& Buehler, 2008). The United States has a much higher proportion of cyclists aged 16-39 when compared to these European countries, which are more accessible to both younger and older age groups (Pucher \& Renne, 2003). Effective bicycle infrastructure should have ridership from all age groups.

\section{Saskatoon's Bicycle Boulevard}

Saskatoon is a relatively flat prairie city in the Canadian province of Saskatchewan. The city experiences significant seasonal changes with hot dry summers and long cold winters. Saskatoon's census metropolitan area population was 260,600 in 2011 (Statistics Canada, 2012). At this time, cycling accounted for $2.0 \%$ of commuter trips (Statistics Canada, 2011). There is very little data regarding cyclist numbers on specific routes within the City of Saskatoon.

Saskatoon's bicycle boulevard grew out of the Saskatoon Speaks public engagement initiative, where citizens made clear that they value the environment and ease of mobility. Based on Saskatoon Speaks, the city began developing an integrated transportation network that includes cycling. Funding for the bicycle boulevard was approved in December 2011 and construction was completed in 2012. The boulevard forms the inner-city component of the larger Blairmore Bikeway, which also includes a multi-use path that services Saskatoon's more distant western suburbs. Saskatoon defines a bicycle boulevard as "a street or series of streets that gives priority to cyclists while [maintaining] local access for motor vehicles." The city goes on to say, "Motor vehicles are not restricted on the bike boulevard, but are discouraged because it's a route where cyclists are given priority" (City of Saskatoon, 2012, p. 2). The city states that cyclists of all ages and skill levels should be able to use the boulevard.

\section{Framing the Research Problem}

This study examines the effectiveness of Saskatoon's bicycle boulevard with respect to NACTO (2012) guidelines, using an infrastructure inventory, traffic counts, and a user intercept survey. The study examines which areas of the boulevard users perceive as safe or unsafe and also observes demographic characteristics of its users to indicate how well the boulevard is functioning. Saskatoon's bicycle boulevard is a new piece of infrastructure and no report on its effectiveness has been created thus far. This report helps to fill this research gap.

While there is not a significant amount of literature regarding the evaluation of bicycle boulevards, Walker, Tresidder, and Birk (2009) provide a description of several case studies from throughout the United States, complete with "Lessons Learned." Common themes in these case studies include the need for public engagement in boulevard implementation, for various traffic calming installations, and for continuing evaluation of each bicycle boulevard. There is no established standard for the evaluation of bicycle boulevards.

It is interesting to note that there is a contradiction in how Saskatoon defines a bicycle boulevard and how it views motor traffic on the boulevard. The city claims to "give priority to cyclists" (City of Saskatoon, 2012) while not restricting motor vehicles. This study observes how this contradiction has affected the functionality of the boulevard. Not everyone in Saskatoon is pleased with the bicycle boulevard's implementation. The local cycling advocacy group Saskatoon Cycles raised concerns that the infrastructure is "not a true bike boulevard" (Hutton, 2012, para. 8) due to an apparent lack of access control for motor vehicles to the boulevard.

Cycling has the potential to provide Saskatoon with many benefits. This study determines if the existing cycling infrastructure is adequate for cycling to reach its maximum potential and make Saskatoon a safer, more efficient, and more dynamic city. 


\section{Methodology}

\section{Location Information}

The bicycle boulevard begins at the western edge of the Central Business District in Saskatoon and runs westward. The boulevard runs adjacent to $22^{\text {nd }}$ Street West, a major motor-traffic thoroughfare and commercial area, for its duration. The boulevard is thirty blocks in length (3.5 $\mathrm{km}$ ), beginning in the East at the Intersection of Idylwyld Drive and Jamieson Street before quickly turning onto $23^{\text {rd }}$ Street and extending to Vancouver Avenue in the West (See Figure 1). At its western terminus, the boulevard connects with a pedestrian/cyclist path (the Blairmore Bikeway) which continues to Saskatoon's western suburbs.
Figure 1 displays the field site boundaries pertaining to Saskatoon's bicycle boulevard. Also displayed are the five locations of traffic counts used in this study (see Methodolgy).

\section{Site Characteristics}

Saskatoon's Bicycle Boulevard consists of $23^{\text {rd }}$ Street West. This street has been retrofitted with infrastructure with the goal of making the route more bike friendly. The boulevard runs through low-density residential areas for twenty-two of its thirty blocks. Near Idylwyld Drive, the boulevard spans eight blocks with commercial and light industrial uses (See Figures 2 and 3). The boulevard runs through three neighborhoods from east to west: Caswell Hill, Westmount, and Mount Royal respectively. These

Figure 1: Route of Saskatoon's Bicycle Boulevard and Traffic Count Locations. Adapted from Saskatoon, SK - Google Maps, by Google, retrieved from http://www.google.ca/maps/ Copyright 2013 by Google.

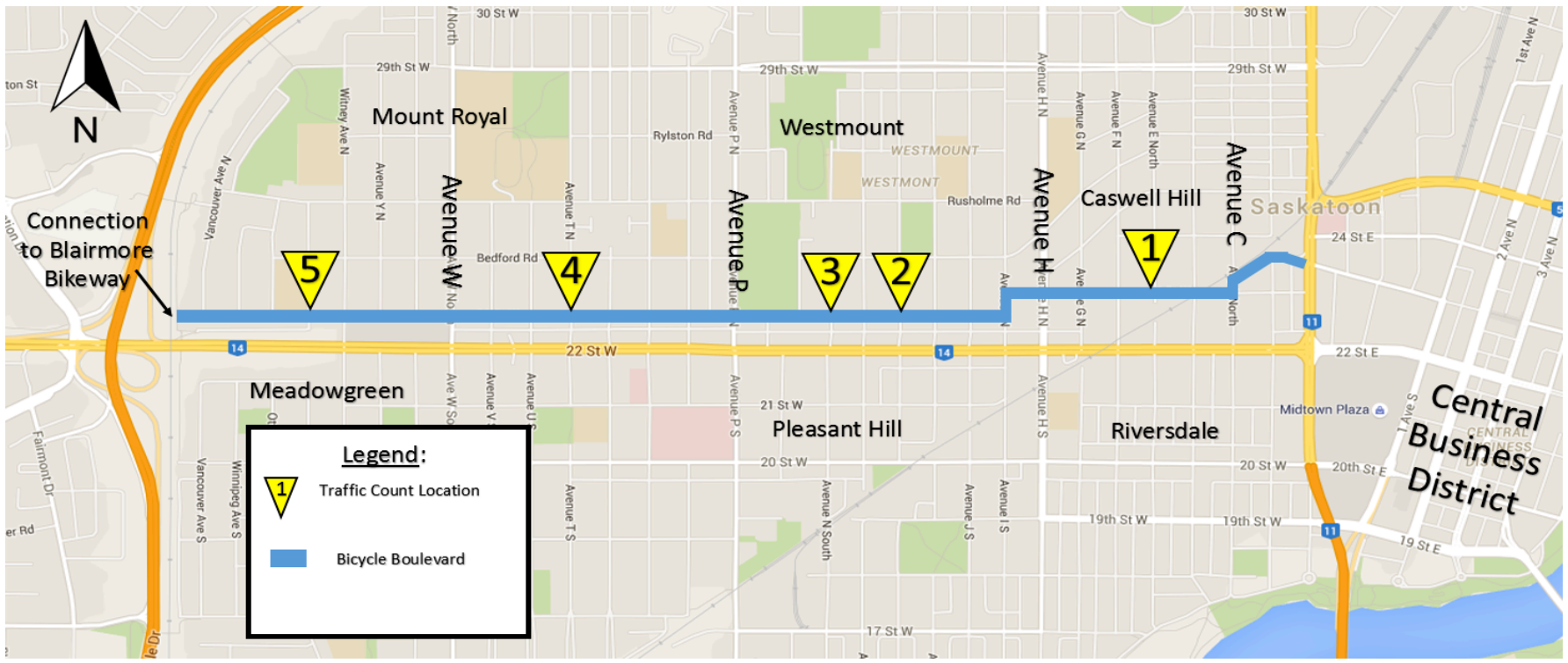

Figure 2: Storage yard near Avenue E

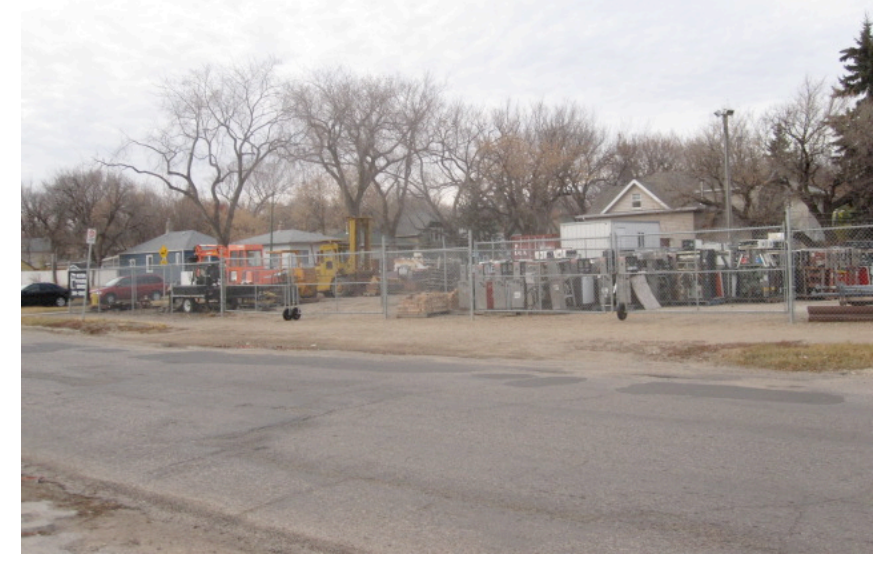

three neighborhoods have average and median incomes significantly lower than those for Saskatoon as a whole (City of Saskatoon, 2011). 
Figure 3: Residential area near Avenue T

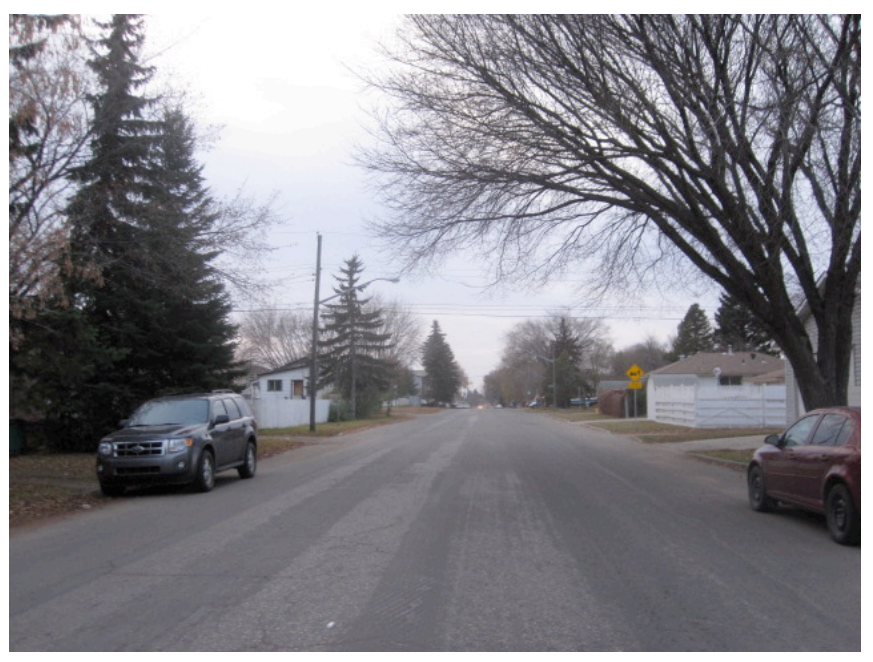

\section{Inventory of Bicycle Infrastructure}

This study first took an inventory of the bicycleoriented infrastructure currently in place on the boulevard as well as on streets that intersect the boulevard. The inventory included traffic-calming infrastructure and signage/pavement markings with respect to NACTO (2012) standards for bike boulevard design. The type and location of this infrastructure were recorded and pictures were taken for documentation. This information was later compared with NACTO (2012) standards (see Discussion).

\section{Traffic Counts and Cyclist Gender Counts}

At five intersections throughout the boulevard, traffic counts of cyclists and motor vehicles were conducted in order to gain an understanding of the boulevard's usage. Only traffic going through the intersections in the EastWest/West-East directions was recorded. Vehicles turning on and off of the boulevard at these intersections were not included in traffic counts because these vehicles do not necessarily represent those using the boulevard as a major East-West route and are more likely to be local traffic, which is always permitted on a bicycle boulevard.

The five traffic count sites were picked to adequately cover the entirety of the boulevard and to provide traffic data near key infrastructure installations (see Figure 11). Motorized traffic counts included any form of transportation not human-powered. For cyclists, the observed gender of the riders was recorded to assist in later analysis of the effectiveness of the boulevard (see Literature Review). Pedestrians were not included in traffic counts.

Traffic counts were carried out on five different days in late September and early October 2013 when weather was relatively calm with little wind and no precipitation. Due to limitations in study duration, and to maintain a level of consistency in data, traffic counts were limited to weekday afternoons. Traffic counts were performed from 4:45 p.m. to 5:30 p.m. on weekdays (two Mondays, two Tuesdays, and one Thursday) in order to include commuters returning home from work with reasonable daylight. Temperatures on four of the five days ranged from the mid-teens to midtwenties $\left(15^{\circ} \mathrm{C}\right.$ to $\left.23^{\circ} \mathrm{C}\right)$ with the exception being the day corresponding to site five when the temperature was at $12^{\circ} \mathrm{C}$.

\section{Cyclist Intercept Survey}

In order to better understand the characteristics of cyclists who use the boulevard and their perceptions of the boulevard, a survey was conducted. Cyclists were flagged down at various points on the boulevard throughout the duration of the study. Most of the surveys were conducted at the same locations as the traffic counts and all surveys were conducted in the same time window as the traffic counts ( $4: 45$ to $5: 30 \mathrm{pm})$.

The survey represents an example of purposive stakeholder sampling, as it was specifically designed to target certain stakeholders (the cyclists) in order to evaluate the bicycle boulevard. Due to the uncertainty in the number of cyclists using the boulevard, every cyclist possible was approached with the survey. However, not all cyclists could be included in the survey. Those who happened to pass while a survey was being conducted were not included and those who passed at periods of intense motor-traffic were also sometimes missed. It was observed that many people regularly use the boulevard on different days, so cyclists that were missed on one day were often included on a different day. Cyclists could not complete the survey twice if they were flagged down on more than one occasion. Some cyclists filled out the survey themselves while others preferred to answer questions orally so that they did have to dismount their bicycles or remove their gloves.

The survey consists of ten questions, seven quantitative and three qualitative. The questions were developed based on NACTO guidelines of what makes a successful bike boulevard. The quantitative survey is as follows:

1. Determination of participant age by ten-year age interval

2. Determination of participant gender

3. Are you aware that $23^{\text {rd }}$ Street West from Idylwyld Drive to Vancouver Avenue is designated as a bicycle boulevard (bicycles have priority over cars)? (yes/no)

4. Do you feel protected from car traffic while biking on $23^{\text {rd }}$ Street (bike boulevard)? (yes/no)

5. Cars are discouraged from using $23^{\text {rd }}$ Street. (Agree/Disagree) 
6. Cars travel slower on $23^{\text {rd }}$ Street than on other streets. (Agree/Disagree)

7. How safe is it for cyclists to use $23^{\text {rd }}$ Street (bike boulevard)? (Answered on a 1-5 scale with 1 being "Not safe" and 5 being "Very Safe")

The three qualitative questions are:

8. How can $23^{\text {rd }}$ Street (bike boulevard) be improved for cyclists?

9. What part of $23^{\text {rd }}$ Street (bike boulevard) is safest for cyclists? Why?

10. What part of $23^{\text {rd }}$ Street (bike boulevard) is least safe for cyclists? Why?

\section{Analysis Approach}

The data gathered with the traffic counts and quantitative survey questions were represented in tables and graphs. The safety related qualitative survey questions were analyzed and represented on maps of the site area, and the qualitative question relating to potential improvements was analyzed using data coding (see Table 5). This data gathered from the five different sites, as well as from the entire boulevard, was then compared with the infrastructure information found in the infrastructure survey. By comparing demographic information, traffic counts, perceptions of traffic, perceptions of safety, and suggestions for improvements with existing infrastructure, common themes began to emerge from the data regarding how well the boulevard is functioning and what improvements can be made. This analysis is done through a NACTO (2012) lens regarding bicycle boulevard design and is based on the existing literature regarding urban cycling (see Literature Review).

\section{Results}

\section{Infrastructure Inventory}

The route. The bicycle boulevard route complies with NACTO (2012) standards. It is continuous and of adequate length. The vast majority of intersections contain yield or stop signs oriented towards the intersecting streets, so that cyclists do not have to stop. Six out of twenty-nine intersections (Avenues $\mathrm{C}, \mathrm{H}, \mathrm{I}, \mathrm{P}, \mathrm{W}$ and Witney) force cyclists to stop for cross-traffic. The route is in a largely residential area, except from Idylwyld to Avenue F, where it

Figure 4: Locations of signage and pavement parkings (Avenue $O$ to Vancouver Avenue). Reprinted from "Bike

Boulevard" Frequently Asked Questions, by City of Saskatoon, retrieved from

http://www.saskatoon.ca/DEPARTMENTS/Infrastructure\%20Services/Transportation/

Cycling/CyclingLanesPathwaysAndTrails/Documents/Frequently\%2oAsked\%20Questions\%20-

$\% 20 B i k e \% 20 B o u l e v a r d$.pdf Copyright 2012 by City of Saskatoon

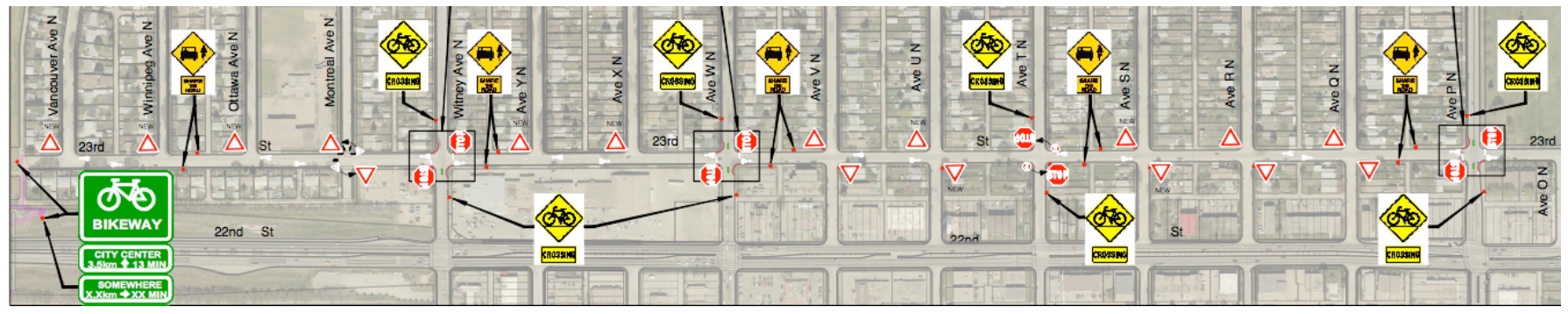

Figure 5: Locations of signage and pavement markings (Idylwyld Drive to Avenue O). Reprinted from "Bike Boulevard" Frequently Asked Questions, by City of Saskatoon, retrieved from

http://www.saskatoon.ca/DEPARTMENTS/Infrastructure\%20Services/Transportation/

Cycling/CyclingLanesPathwaysAndTrails/Documents/Frequently\%20Asked\%20Questions\%20-

$\% 20 B i k e \% 20 B o u l e v a r d$.pdf Copyright 2012 by City of Saskatoon

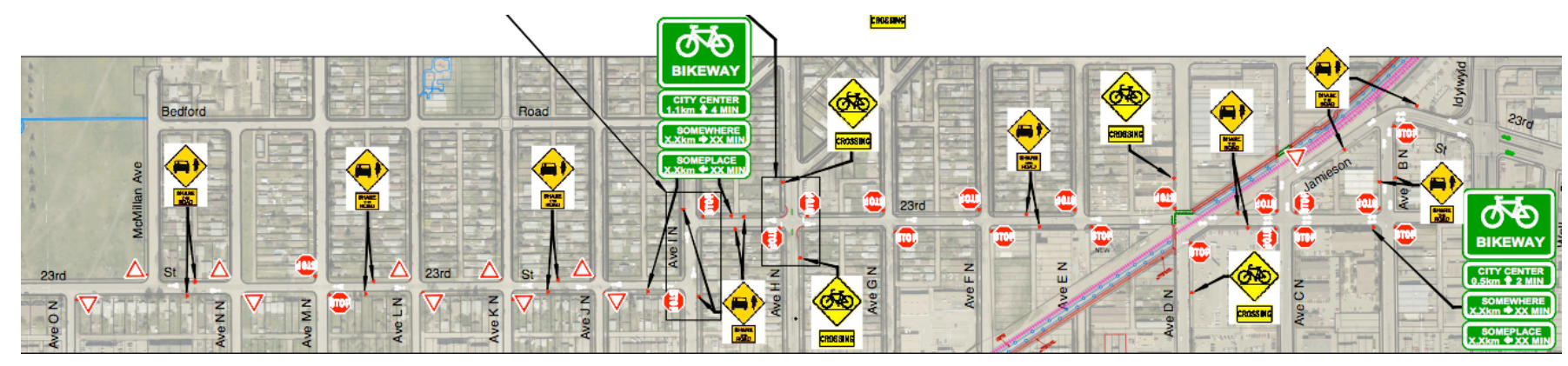

University of Saskatchewan Undergraduate Research Journal 
enters an area of light industrial and commercial use. The route runs parallel and adjacent to $22^{\text {nd }}$ Street, a major commercial corridor, thus offering access to numerous commercial destinations.

Signage and markings. The bicycle boulevard contains abundant signage and pavement markings, in accordance with NACTO (2012) standards. Examples of pavement markings, way-finding signs, and modified street signs, as well as the locations of major signage infrastructure, can be seen in Figures 4, 5, 6, and 7 .

Figure 6: Example of custom street signage on the bicycle boulevard

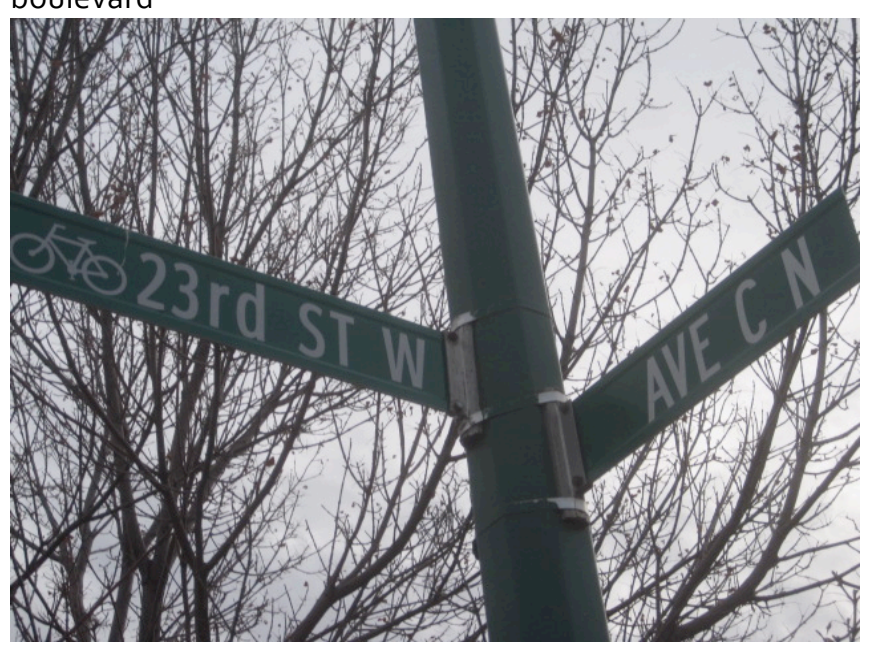

Figure 7: Way-finding sign on the bicycle boulevard

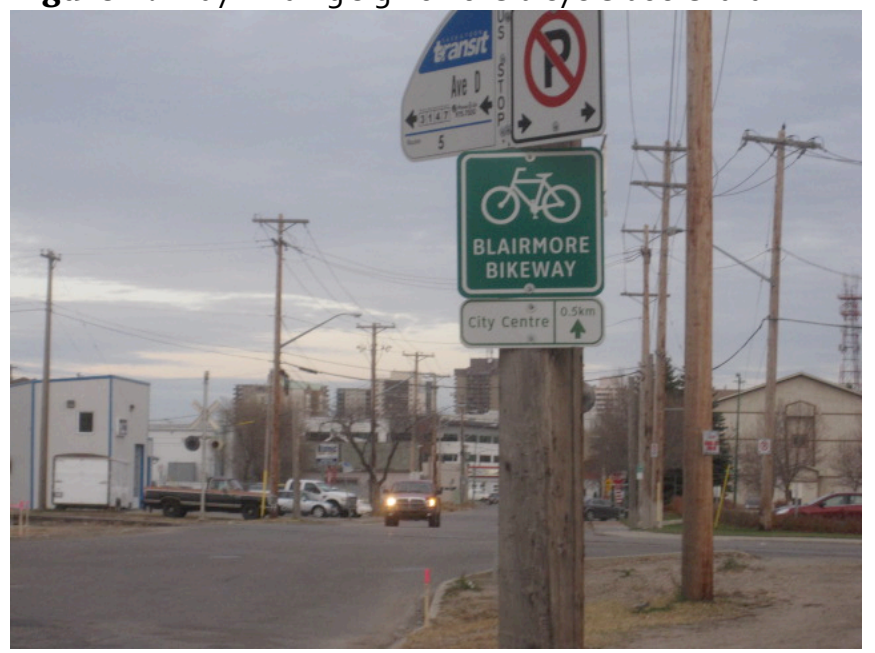

\section{Traffic Calming}

The city has installed traffic-calming infrastructure, mostly to target motor traffic speeds but not volumes (see Table 2). This infrastructure includes street narrowing, traffic circles, and a choker that restricts motor traffic to one lane at a time.

Table 2: Inventory of Bicycle Boulevard Traffic Calming Measures

\begin{tabular}{|c|c|c|}
\hline $\begin{array}{l}\text { Traffic Calming } \\
\text { Measure }\end{array}$ & $\begin{array}{l}\text { Potential Effect } \\
\text { on Motor Traffic }\end{array}$ & $\begin{array}{l}\text { Location(s) (see } \\
\text { Figure 11) }\end{array}$ \\
\hline $\begin{array}{l}\text { Street } \\
\text { Narrowing in the } \\
\text { form of curb } \\
\text { extensions or } \\
\text { central concrete } \\
\text { medians (see } \\
\text { Figure } 8 \text { ) }\end{array}$ & $\begin{array}{l}\text { Decrease in } \\
\text { speed }\end{array}$ & $\begin{array}{l}\text { Installed on four } \\
\text { intersecting streets } \\
\text { that require cyclists } \\
\text { to stop for motor } \\
\text { traffic (Avenues } \mathrm{H} \text {, } \\
\mathrm{P}, \mathrm{W} \text {, and Witney); } \\
\text { Additional } \\
\text { narrowing oriented } \\
\text { towards both } 23^{\text {rd }} \\
\text { Street and } \\
\text { intersecting street } \\
\text { adjacent to school } \\
\text { on Montreal Ave. }\end{array}$ \\
\hline $\begin{array}{l}\text { Traffic Circles } \\
\text { (see Figure 9) }\end{array}$ & $\begin{array}{l}\text { Decrease in } \\
\text { speed; minimal } \\
\text { decrease in } \\
\text { volume }\end{array}$ & $\begin{array}{l}\text { Installed at } \\
\text { intersections of } 23^{\text {rd }} \\
\text { Street and Avenues } \\
\text { K and N. }\end{array}$ \\
\hline $\begin{array}{l}\text { Choker (see } \\
\text { Figure 10) }\end{array}$ & $\begin{array}{l}\text { Decrease in } \\
\text { speed and } \\
\text { volume }\end{array}$ & $\begin{array}{l}\text { Installed on bike } \\
\text { boulevard between } \\
\text { Avenue E and } \\
\text { Avenue F. }\end{array}$ \\
\hline
\end{tabular}

Figure 8: Street narrowing via medians and curb extensions at Avenue $P$

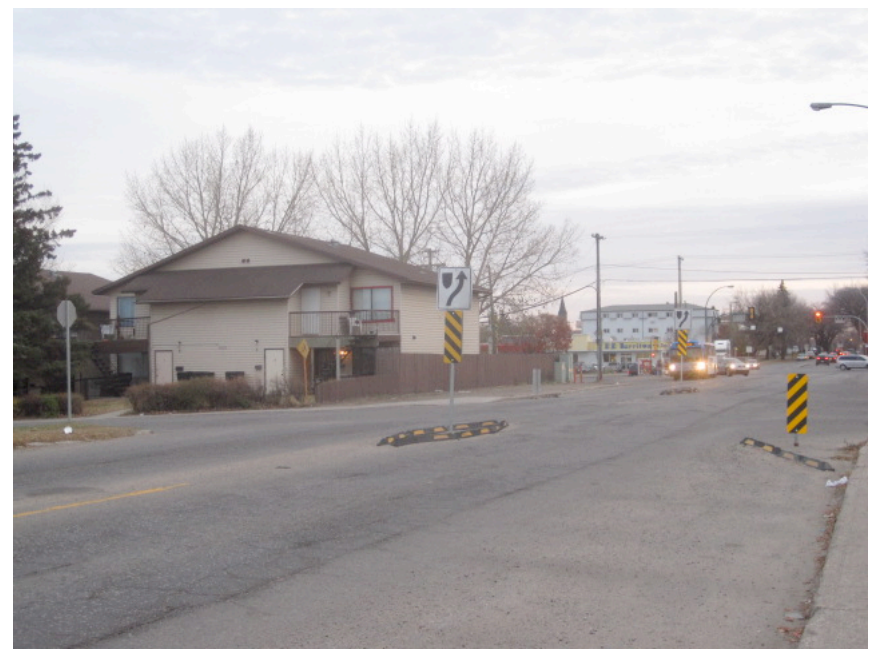


Figure 9: Traffic circle at Avenue $\mathrm{K}$

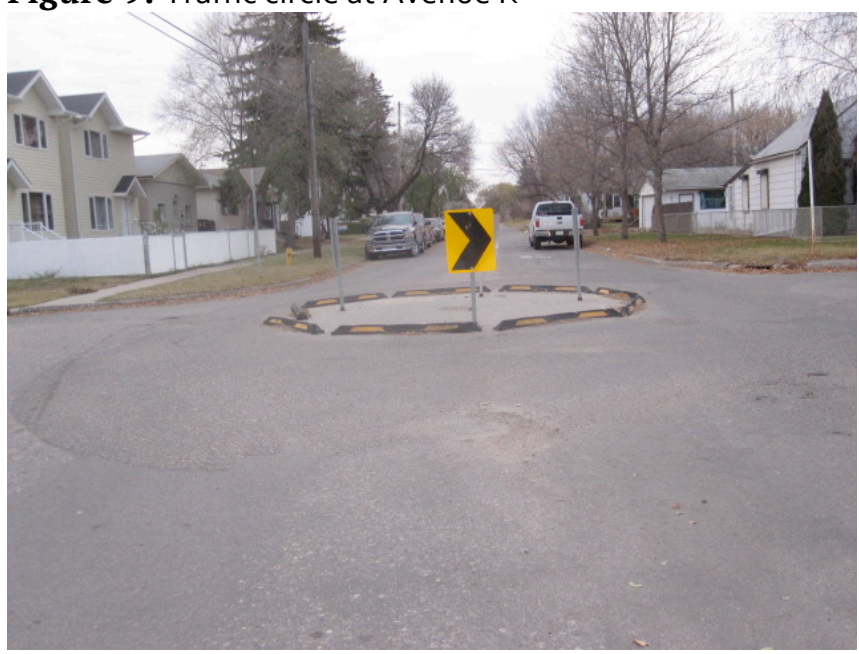

Figure 10: Choker near Avenue $\mathrm{E}$

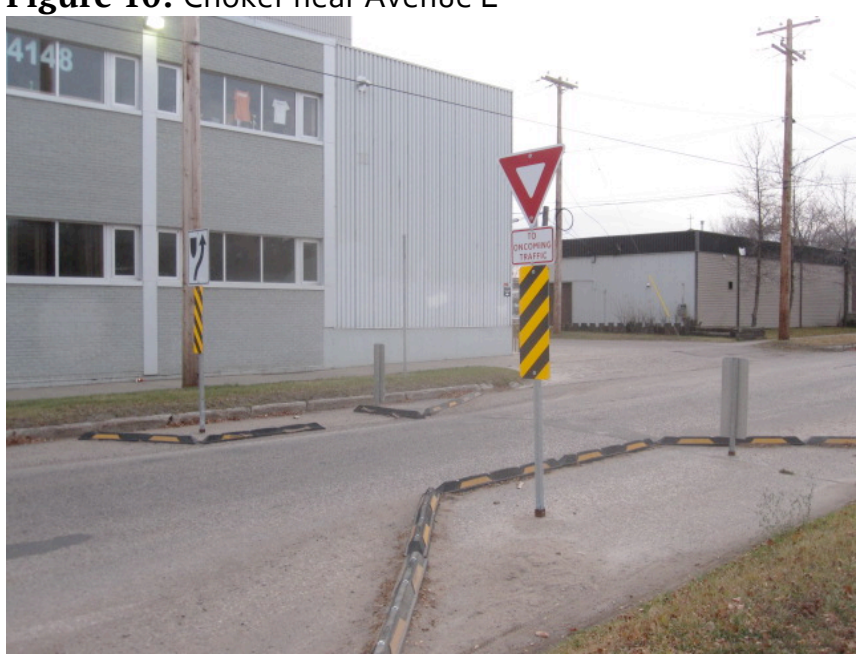

Figure 10 (above) displays how traffic is only permitted in one direction at a time in a choker. Note that in this choker design cyclists are funneled in with cars.

\section{Treatment of Intersections}

The boulevard contains six intersections (Avenues $C$, $\mathrm{H}, \mathrm{I}, \mathrm{P}, \mathrm{W}$ and Witney) where cyclists must yield to motor vehicle cross-traffic, including one offset intersection at Avenue I. All of these intersections feature signage oriented towards the intersecting street, to raise awareness of cyclists and the bike boulevard. With the exception of Avenue I, these intersections contain street narrowing oriented towards the intersecting street, to reduce traffic speeds. The offset intersection contains no central medians or bike lanes to ease cyclist crossing. Montreal Avenue does not involve cyclists yielding to motorists but still contains curb extensions and street narrowing oriented towards all streets so as to reduce traffic speeds adjacent to a school.

\section{Traffic Counts and Cyclist Gender Balance}

Traffic counts and observation of the gender balance of cyclists using the boulevard were performed at five locations on the boulevard (see Figure 11). The results of these traffic counts are displayed in Table 3 (below).

\section{Summary of Data}

It is clear from all sites that cyclists are not the primary users of the bike boulevard. Bicycles, as a percentage of total observed vehicles, range from a low of $3 \%$ at site one to a high of $16 \%$ at site three. It appears that cyclists represent a higher proportion of users on the boulevard towards its middle and a lower proportion of users at its ends. When averaging the data of all sites, cyclists represent $8 \%$ of all observed vehicles.

In all cases, male cyclists greatly outnumber female cyclists on the boulevard. Female cyclists range from a low of $13 \%$ of total cyclists for sites two and three to a high of $38 \%$ for site one. It should be noted that as the total number of cyclists decreases, the proportion of female cyclists increases. It is difficult to adequately judge these proportions from a very small number of cyclists (for example, three cyclists at site five). When data from all sites is averaged, $19 \%$ of all cyclists were observed to be female.

\section{Survey Results}

\section{Question 1: Age of Survey Participants (See} Figure 12)

Figure 12: Age of survey participants divided by gender

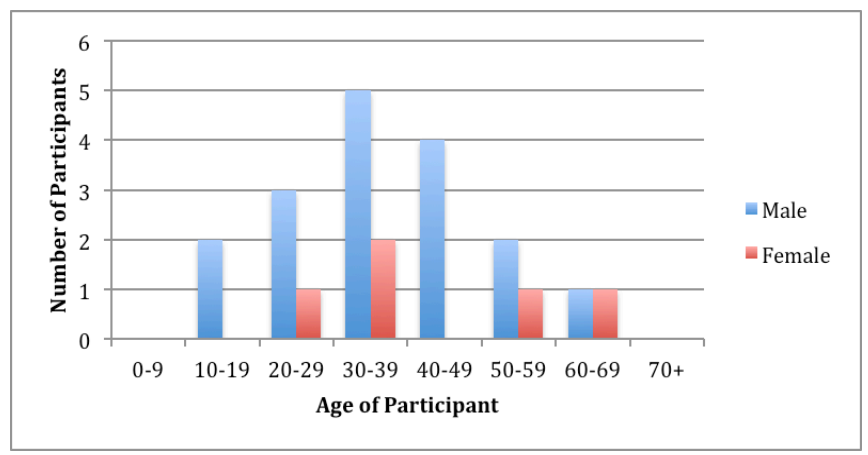


Figure 11: Location of traffic calming infrastructure and traffic count locations within bike boulevard. Adapted from Saskatoon, SK - Google Maps, by Google, retrieved from http://www.google.ca/maps/ Copyright 2013 by Google.

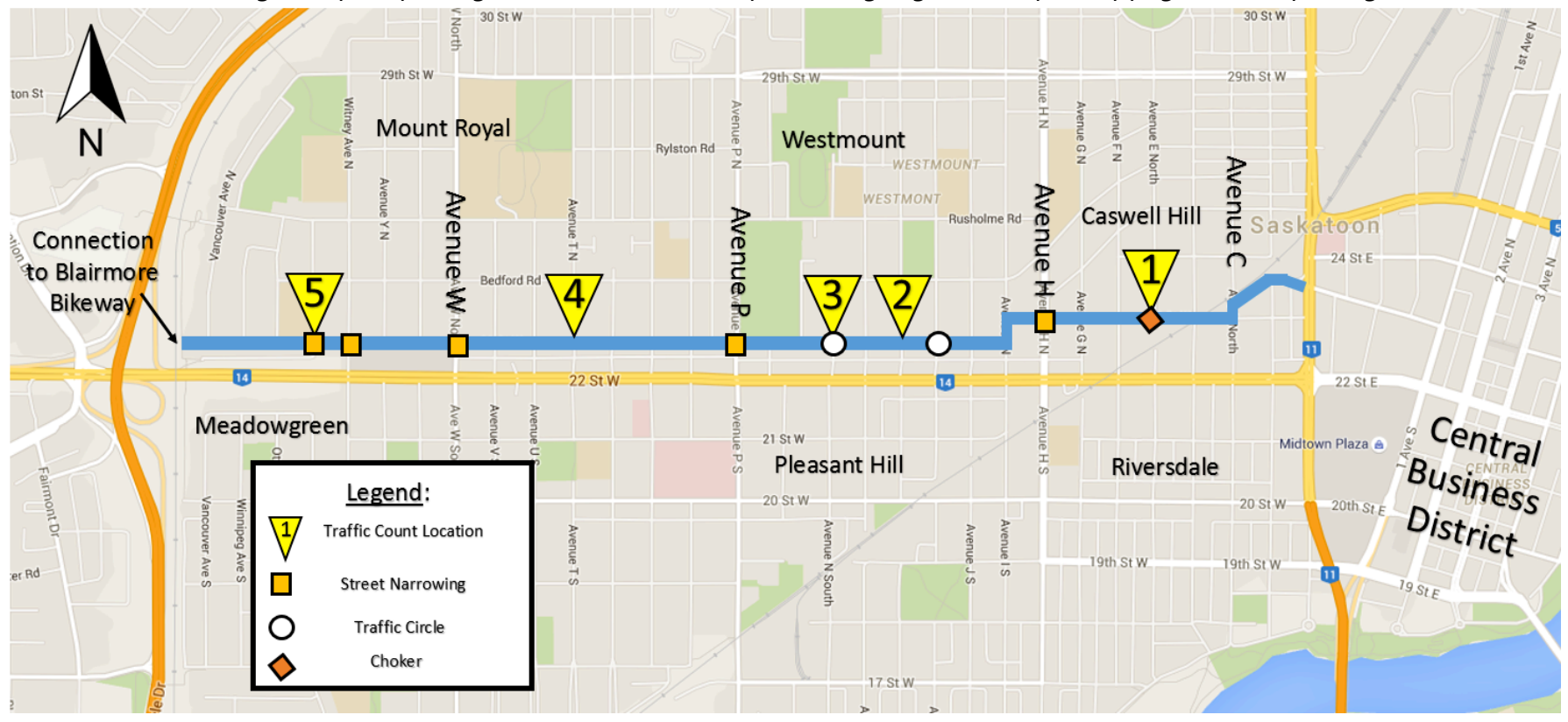

Table 3: Quantitative Results of Traffic Counts

\begin{tabular}{|c|c|c|c|c|c|c|}
\hline Site \# & Location & $\begin{array}{l}\text { Number of } \\
\text { Cyclists }\end{array}$ & $\begin{array}{l}\text { Number of } \\
\text { Motorized Vehicles }\end{array}$ & $\begin{array}{l}\text { \% Cyclist } \\
\text { Users }\end{array}$ & $\begin{array}{l}\text { \% Female } \\
\text { Cyclists }\end{array}$ & Notes: \\
\hline 1 & $\begin{array}{l}23^{\text {rd }} \text { Street and } \\
\text { Avenue } \mathrm{E}\end{array}$ & 8 & 233 & 3 & 38 & $\begin{array}{l}\text { This site was } \\
\text { adjacent to the } \\
\text { installed choker. }\end{array}$ \\
\hline 2 & $\begin{array}{l}23^{\text {rd }} \text { Street and } \\
\text { Avenue } L\end{array}$ & 8 & 64 & 11 & 13 & $\begin{array}{l}\text { This site was } \\
\text { between the } \\
\text { boulevard's two } \\
\text { traffic circles. }\end{array}$ \\
\hline 3 & $\begin{array}{l}23^{\text {rd }} \text { Street and } \\
\text { Avenue } \mathrm{N}\end{array}$ & 15 & 81 & 16 & 13 & $\begin{array}{l}\text { This site was at the } \\
\text { location of one the } \\
\text { traffic circles. }\end{array}$ \\
\hline 4 & $\begin{array}{l}23^{\text {rd }} \text { Street and } \\
\text { Avenue } T\end{array}$ & 14 & 108 & 11 & 14 & $\begin{array}{l}\text { This site featured } \\
\text { wide open roads } \\
\text { with few parked } \\
\text { cars. }\end{array}$ \\
\hline 5 & $\begin{array}{l}23^{\text {rd }} \text { Street and } \\
\text { Montreal Avenue }\end{array}$ & 3 & 60 & 5 & 33 & $\begin{array}{l}\text { This site was } \\
\text { adjacent to a road } \\
\text { narrowing and } \\
\text { installed central } \\
\text { median. }\end{array}$ \\
\hline Total & -- & 48 & 546 & -- & -- & -- \\
\hline Average & -- & -- & -- & 8 & 19 & -- \\
\hline
\end{tabular}

Figure 12 displays that the age of the survey's 22 participants peaks in the 30-39 range for both males and females. The average ages for males, females, and their total all fall in this range. There were no participants in the $0-9$ or $70+$ age range. It should be noted that this data represents a relatively small sample size and may not be an accurate representation of the actual user characteristics for the boulevard.
Table 4 (below) displays the results of survey questions two through six. This data indicates that the majority of surveyed cyclists were male, in a proportion similar to that observed in traffic counts. Survey participants were generally aware that $23^{\text {rd }}$ Street was designated as a bicycle boulevard. Notably, participants 
Table 4: Percentage Results of Survey Questions 2 - 6

\begin{tabular}{|c|c|c|c|c|c|c|}
\hline Question & Result & & & & & \\
\hline & Male & Female & Yes & No & Agree & Disagree \\
\hline 2) Gender of Survey Participants & 77 & 23 & -- & -- & -- & -- \\
\hline $\begin{array}{l}\text { 3) Are you aware that } 23^{\text {rd }} \text { Street West from } \\
\text { Idylwyld Drive to Vancouver Ave. is designated } \\
\text { as a bicycle boulevard (bicycles have priority } \\
\text { over cars)? }\end{array}$ & -- & -- & 77 & 23 & -- & -- \\
\hline $\begin{array}{l}\text { 4) Do you feel protected from car traffic while } \\
\text { biking on } 23^{\text {rd }} \text { Street (bicycle boulevard)? }\end{array}$ & -- & -- & 50 & 50 & -- & -- \\
\hline 5) Cars are discouraged from using $23^{\text {rd }}$ Street. & -- & -- & -- & -- & 14 & 86 \\
\hline $\begin{array}{l}\text { 6) Cars travel slower on } 23^{\text {rd }} \text { Street than on } \\
\text { other streets. }\end{array}$ & -- & -- & -- & -- & 73 & 27 \\
\hline
\end{tabular}

gave mixed reviews regarding perceptions of safety on the boulevard. Participants appear to perceive that, while cars travel slower on the boulevard, these vehicles are not discouraged from using the bike route.

\section{Question 7: How safe is it to use $23^{\text {rd }}$ Street (bike boulevard)?}

Figure 13 (below) shows that cyclists have neutral to positive feelings towards the safety of the bike boulevard on a scale of 1-5 with 20 out of 22 participants giving the boulevard a rank of 3 or greater. The 0.5 values for ratings 1 and 2 represent a participant who gave the boulevard a rating of 1.5 .

Figure 13: Participant perceptions of safety on bike boulevard.

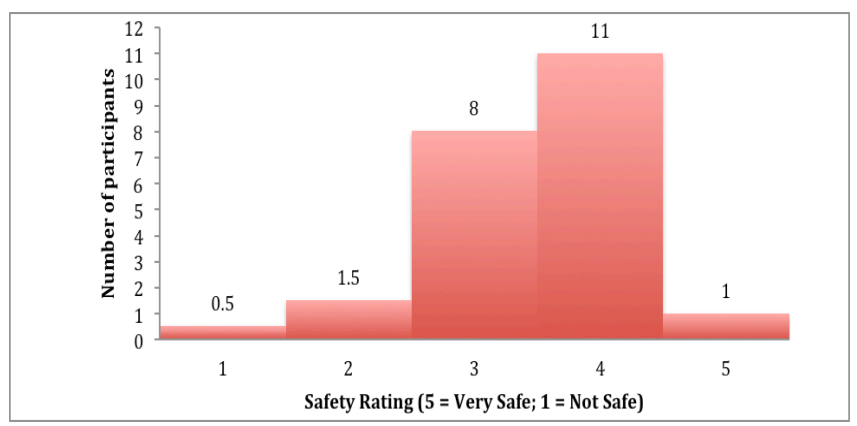

Question 8: How can $23^{\text {rd }}$ Street (bike boulevard) be improved for cyclists (see Table 5)?

\section{Summary of Data Trends for Question 8:}

Seven out of twenty-two participants see a need for the bike boulevard to be re-surfaced. These participants are frustrated with what they perceive as an excessive amount of bumps and potholes.

Six out of twenty-two participants identified improvements having to do with existing traffic calming measures. Cyclists do not like being mixed with motorists at the traffic circles and at the choker, and some participants view the infrastructure as ineffective in adequately calming traffic. Two out of twenty-two participants saw the addition of more traffic circles as a way to improve the boulevard.

Five out of twenty-two survey participants saw that the bike boulevard could be improved by having a greater separation between cyclists and motor vehicles. Suggestions included the creation bike-only areas by creating bike lanes or barriers for cars (4 participants).

Three out of twenty-two participants identified intersections where cyclists yield to car traffic as needing improvement. Suggestions included creating better signage and visibility to increase motorist awareness of the bike boulevard and eliminating all stop signs oriented towards cyclists.

One out of twenty-two participants identified the lack of sidewalks in many parts of the boulevard as a problem. This participant saw that pedestrians often walk on the bike boulevard and must be avoided by cyclists.

Three out of twenty-two participants thought the bike boulevard did not need any improvements. Three out of twenty-two participants were unsure of what improvements were needed. 
The Effectiveness of Saskatoon's Bicycle Boulevard (Surkan)

Table 5: Data Coding for Survey Question 8

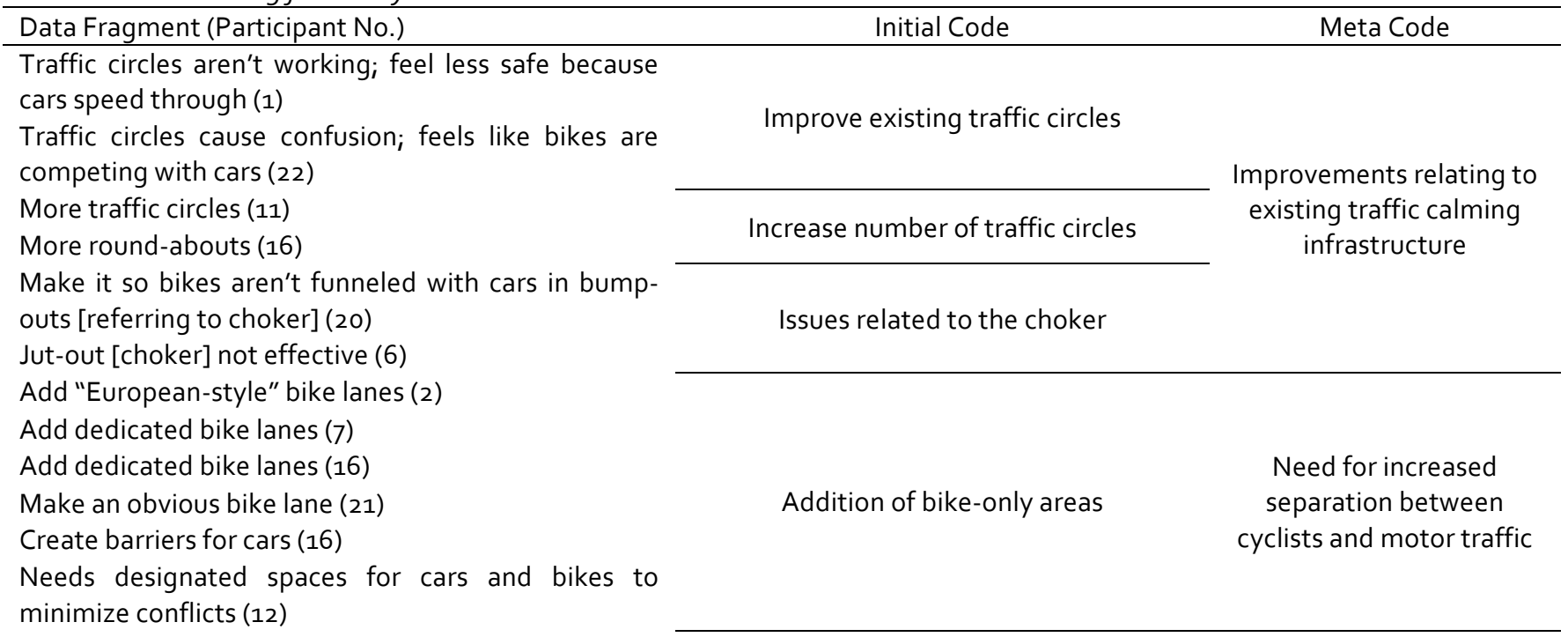

Re-pave the street (4)

Pavement issues (5)

Too bumpy (6)

Potholes fixed (7)

Fix the potholes (18)

Re-pave (20)

Repair road (21)

Better signage for cars at intersections (14)

Trim greenery around intersections to improve visibility (14)

Better signage (17)

Remove stop signs for bicycles (6)

Install sidewalks to remove pedestrians from the road

(13)

It's perfect (8)

It's pretty safe (10)

It's good (15)

Unsure (3)

Not sure (9)

Unsure (19)

\section{Questions 9: What part of $23^{\text {rd }}$ Street (bike} boulevard) is safest for cyclists? Why? (see

\section{Figure 14)}

Figure 14 shows that the areas of the bike boulevard further west (towards Vancouver Avenue) are perceived as safer than areas closer to Idylwyld Drive in the East. Areas with a greater number of responses are perceived to be safer than areas with fewer responses. Areas with lower amounts of traffic were the areas that were recognized as the safest. The area from Avenue $P$ (West of Leif Erickson Park) to the western end of the boulevard is perceived as safe for this reason.
Awareness and visibility for cars at intersections

Issues pertaining to intersections

Issue pertaining to bicyclist convenience at intersections

Specific Misc. issue

Positive feelings; no improvements needed

Unsure of what improvements are needed

It is important to note that a significant proportion (6 participants) identified the area between the traffic circles as safe because of lower traffic. Another participant identified the choker as safe because of less and slower traffic.

The part of the boulevard adjacent to Leif Erickson Park (Avenue $O$ to Avenue $P$ ) was identified as safe. This part of the boulevard features a wide street and a slope that makes eastbound cycling easy. Visibility for both cars and bikes is seen as clear in this area.

Some responses were not included on this map. These responses included that everywhere was safe, that the "middle part" is safe, and that only the grass adjacent to the boulevard is safe. 
Figure 14: Areas of perceived safety on the bike boulevard. Adapted from Saskatoon, SK - Google Maps, by Google, retrieved from http://www.google.ca/maps/ Copyright 2013 by Google.

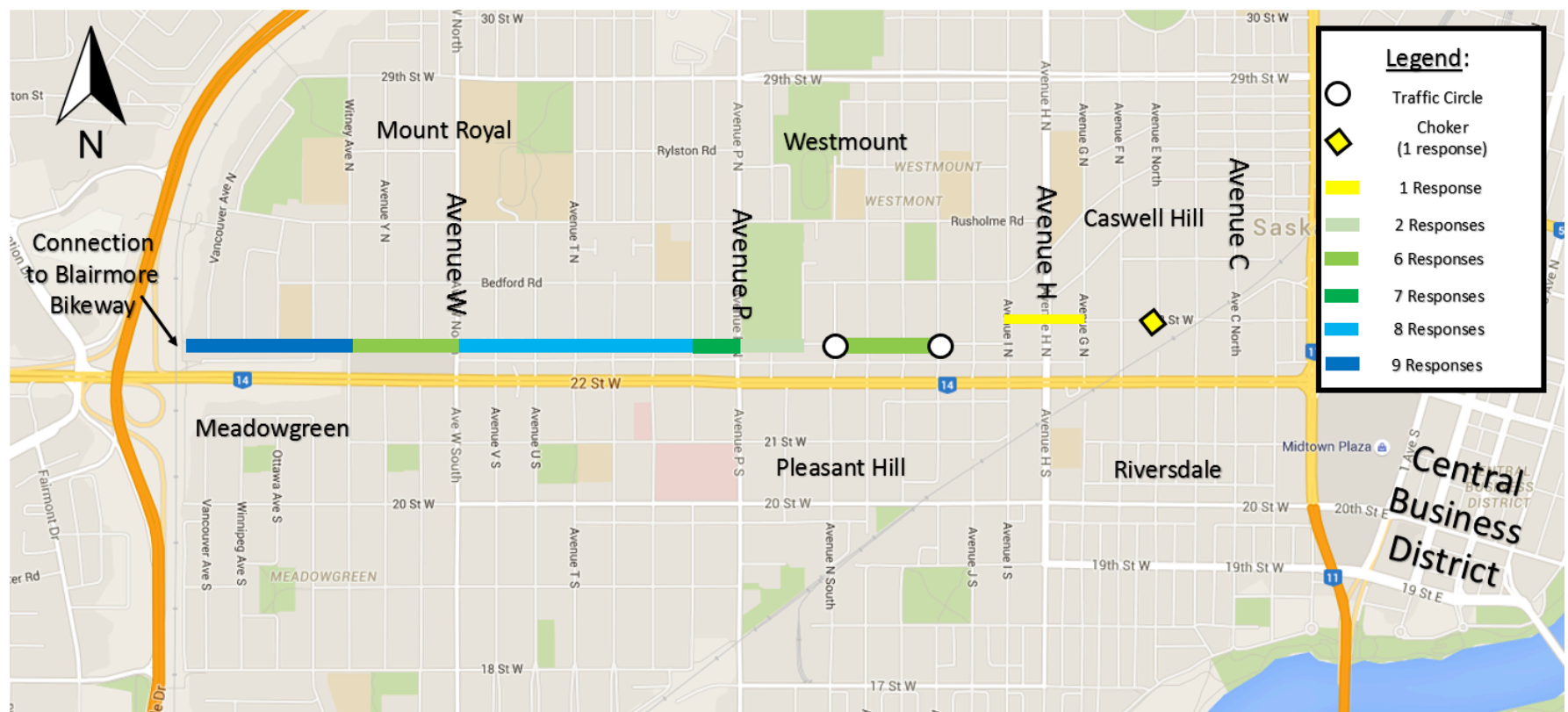

Additionally, one participant had views opposite the others. This participant viewed the area from Idylwyld to Avenue $D$ as safest because the greater amount of traffic meant a lower chance of being a victim of crime. This participant viewed the area as having a high risk for crime.

\section{Question 10: What part of $23^{\text {rd }}$ Street (bike} boulevard) is least safe for cyclists? Why? (see Figure 15)

Figure 15 shows locations of perceived danger for cyclists on the bike boulevard, with areas that have responses being perceived as the least safe. From the figure it is clear that as the boulevard goes towards Idylwyld (Eastern edge) the perception of danger increases. The area near Idylwyld is seen as the most dangerous.

The primary reason for low perceptions of safety was found to be high levels of traffic. Areas with low traffic are perceived as safer than areas with high traffic. Traffic is perceived to decrease as the boulevard moves further from the city center and so safety perceptions increase.

Avenue $P$ is a specific location perceived as especially dangerous due to the fact that bikes must stop at the intersection and then cross a relatively high motor-traffic Avenue. Another area perceived to be especially dangerous is between Avenues $\mathrm{H}$ and $\mathrm{I}$ where the road is in poor condition. Poor roads are a factor in safety perception throughout the boulevard. Although the area between the traffic circles is perceived as relatively safe (see Figure 14), at the circles themselves there is a clear perception of danger. This is because confusion occurs when cars mix with cyclists on the circles. Cyclists feel that they are competing with cars for right of way at the traffic circles.

The four-way stop at Avenue $C$ and every other intersection where cyclists must stop were seen as areas of danger, as cyclists must navigate through car-traffic. The same is true for the offset intersection at Avenue I.

One participant identified Avenue $V$ to Witney Avenue as dangerous because cars shortcut through the bike boulevard to get to $22^{\text {nd }}$ Street destinations.

Responses that were not included in this figure include that the boulevard is not safe anywhere, that the boulevard is not safe at nighttime, areas with high traffic (unspecific), and those who were unsure.

\section{Discussion}

\section{Demographic Indicators}

Figure 15 shows locations of perceived danger for cyclists on the bike boulevard, with areas that have responses being perceived as the least safe. From the figure it is clear that as the boulevard goes towards Idylwyld (Eastern edge) the perception of danger increases. The area near Idylwyld is seen as the most dangerous.

The primary reason for low perceptions of safety was found to be high levels of traffic. Areas with low traffic are perceived as safer than areas with high traffic. Traffic is perceived to decrease as the boulevard moves further from the city center and so safety perceptions increase. 
Figure 15: Areas of perceived danger on bike boulevard. Adapted from Saskatoon, SK - Google Maps, by Google, retrieved from http://www.google.ca/maps/ Copyright 2013 by Google

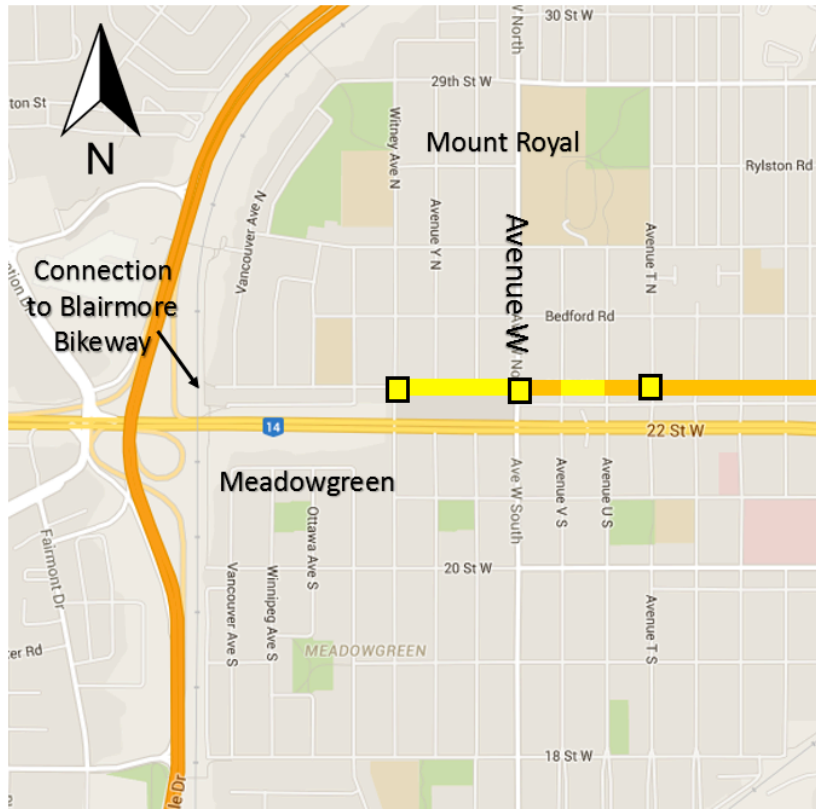

Avenue $P$ is a specific location perceived as especially dangerous due to the fact that bikes must stop at the intersection and then cross a relatively high motor-traffic Avenue. Another area perceived to be especially dangerous is between Avenues $\mathrm{H}$ and $\mathrm{I}$ where the road is in poor condition. Poor roads are a factor in safety perception throughout the boulevard. Although the area between the traffic circles is perceived as relatively safe (see Figure 14), at the circles themselves there is a clear perception of danger. This is because confusion occurs when cars mix with cyclists on the circles. Cyclists feel that they are competing with cars for right of way at the traffic circles.

The four-way stop at Avenue $C$ and every other intersection where cyclists must stop were seen as areas of danger, as cyclists must navigate through car-traffic. The same is true for the offset intersection at Avenue I.

One participant identified Avenue $V$ to Witney Avenue as dangerous because cars shortcut through the bike boulevard to get to $22^{\text {nd }}$ Street destinations.

Responses that were not included in this figure include that the boulevard is not safe anywhere, that the boulevard is not safe at nighttime, areas with high traffic (unspecific), and those who were unsure.

\section{Bicycle Infrastructure through a NACTO (2012) lens}

Saskatoon's bicycle boulevard meets NACTO (2012) design standards with mixed success. The City has done very well with respect to route planning and the use of signage and pavement markings. The logical and continuous route runs on a residential street, is adjacent to many commercial destinations, and creates a connection

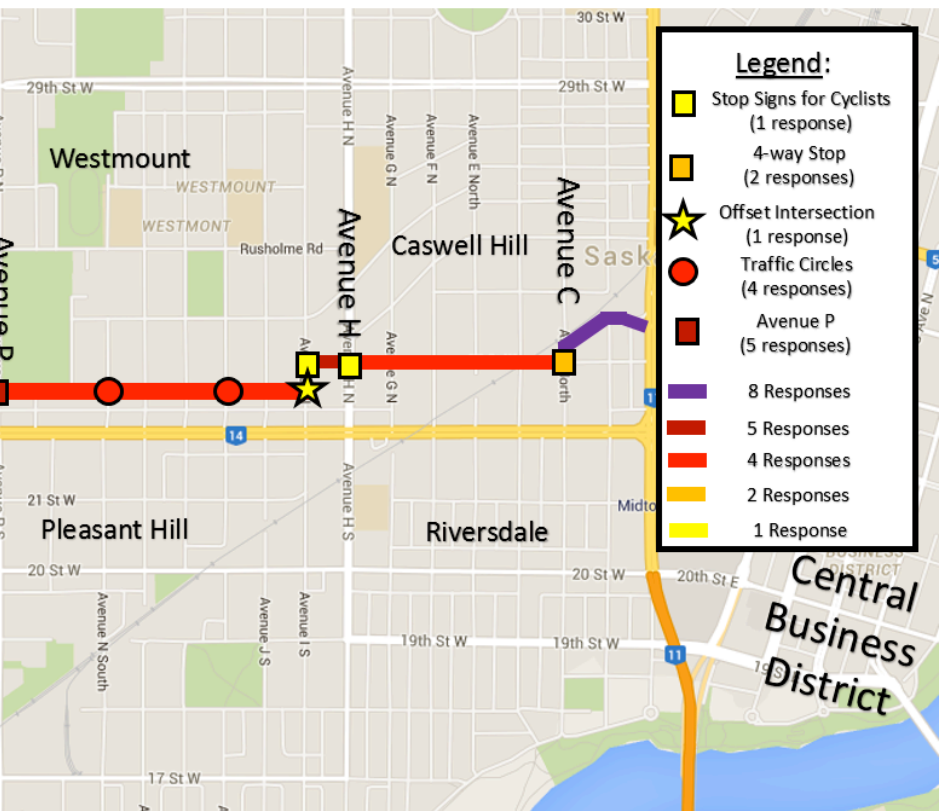

between peoples' homes and the Central Business District. The vast majority of intersecting streets meet yield or stop signs when they reach the boulevard. Throughout this route, one can find customized street signs, way-finding signs, and pavement markings. All of this is in accordance with NACTO (2012).

The city has also made clear investments in traffic calming measures to reduce motorist speeds. These include the choker, two traffic circles, and numerous cases of street narrowing. There are, however, areas that still lack any considerable traffic calming measures, particularly west of Avenue $\mathrm{P}$ where most street narrowing is oriented towards intersecting streets and not towards the boulevard. It is important to note that narrowing streets is one of the least effective methods of lowering traffic speeds (see Table 1) and this is the most common type of traffic calming measure used on the boulevard.

Where the boulevard is clearly lacking is in measures to control the volume of motor traffic usage of the boulevard. In the thirty blocks of the boulevard, the choker is the single example of installed infrastructure that has any significant effect on lowering motor traffic volumes. Thus, Saskatoon's boulevard is missing one of the fundamental elements of a successful bicycle boulevard. Volume control is needed to prevent motorists from taking advantage of measures that are supposed to be targeting cyclists. Without these measures, cyclists must compete with motor traffic for use of the boulevard. The root of this failure in design may be in the self-contradictory approach of the city towards the boulevard (See Literature Review) where prioritizing cyclists can somehow be obtained without placing restrictions on motor traffic. 
User Awareness of the Bicycle Boulevard

Three quarters of cyclists on $23^{\text {rd }}$ Street were found to be aware of the bicycle boulevard's creation. This is a reflection of the effective route and signage/pavement markings on the boulevard that make it clearly visible. As time goes on, user awareness of this new piece of infrastructure is likely to increase.

\section{Motor Traffic Speeds, Infrastructure, and User Perceptions}

It appears that motor traffic speeds are not of major concern with the majority of survey participants agreeing that traffic does travel slower on the boulevard than on other streets. This is likely an indication that traffic-calming measures that aim to reduce speeds are having some success. Successful signage and pavement markings on the boulevard have also likely played a role in keeping motor traffic speeds at acceptable levels. However, this study did not measure any actual motor traffic speeds, so it is unknown if these speeds fall within NACTO (2012) standards.

\section{Motor Traffic Volumes, Infrastructure, and User Perceptions}

The lack of volume control methods on the boulevard is reflected in traffic counts and user perceptions of the boulevard. In all areas on the bicycle boulevard, motor traffic was found to be the dominant type of through traffic on the boulevard, with the site adjacent to the only volume control measure (the choker) seeing the highest number of motor vehicles and motor vehicle proportion of total through traffic. Users of the boulevard are clearly aware of this fact, with the vast majority of participants disagreeing with the statement that cars are discouraged from using the boulevard. Additionally, only $50 \%$ of survey participants feel that they are protected from car traffic while using the boulevard. This percentage should be much higher for a type of infrastructure that supposedly prioritizes cycling.

The lack of volume control is represented in user perceptions of safety and suggestions for how the boulevard could be improved. Although a very small proportion of survey participants rated the entire boulevard as unsafe for cyclists, perceptions of which parts of the boulevard are safest are inversely correlated with perceptions of motor traffic levels. Safe areas are those with less motor traffic, and less safe areas are where cyclists must deal with increased motor traffic. These areas of perceived danger appear to be of three different types: sections of the boulevard that have higher motorized through traffic, intersections where cyclists must navigate motorized cross traffic, and areas where traffic calming measures force cyclists and motor traffic to funnel together. Examples of the three types are the stretch of the boulevard nearest to Idylwyld Drive, the intersection of the boulevard and Avenue $\mathrm{P}$, and the traffic circles, respectively. It should be noted that the field site with the highest measured number of motor vehicles is in an area of perceived danger while the site with lowest number is in the area viewed as safest by cyclists.

It is not surprising that the majority of suggestions for how the boulevard can be improved are related to decreasing the number of areas where cyclists must compete with motorists. Boulevard users want the existing traffic calming measures (the traffic circles and choker) to be redesigned in ways that do not funnel them in with cars, but allow them to proceed through these installations uninhibited. A sizable proportion of participants want clear areas for cyclists, with either clear areas for cars or no cars at all. Several others expressed a need for intersections to be adjusted so that the safety of cyclists is prioritized as they navigate intersecting motor vehicles. Reducing the number of motor vehicles that boulevard users face while cycling appears to be the most desired method for improving the boulevard, and this could be accomplished by incorporating volume control measures.

\section{Other Safety and Convenience Findings}

Two other findings are significant and should be considered in making boulevard improvements. Firstly, the single most common suggestion for how the boulevard can be improved is repaving. While small bumps and potholes may go unnoticed by motorists, they are much more annoying and potentially dangerous for cyclists. Targeting rough sections of the bicycle boulevard for repaving would greatly improve it for cycling.

Secondly, there was a participant who stated fear of crime as a factor in their answers to survey questions. Gehl (2010) states that safety from crime is a "prerequisite for creating inviting well-functioning cities for people" (p. 97). Addressing the actual or perceived crime in the area of the boulevard would likely have a positive impact on the boulevard's effectiveness.

\section{Limitations of Methodology}

The methods used in this study face some important limitations that must be noted. Firstly, cycling is highly weather dependent. Ideally the traffic counts and surveys would all have been carried out on the same day of the week over a period of five weeks. Because of the quickly changing fall weather of Saskatchewan, this study had to be conducted whenever the weather was cooperative, to avoid the risk of a sudden season change. Even with this approach, one day of data gathering occurred on a relatively cool day $\left(12^{\circ} \mathrm{C}\right)$. It is possible that this relatively low temperature may have affected data gathered about 
cyclists that day. Additionally, commuter behaviour likely changes from day to day throughout the week. Although this study was confined to the same time period during weekdays, there is potential that Monday commuting patterns are slightly different from those of Tuesday (for example). These potential differences are not considered.

The cyclist gender balance component of the traffic counts is based on normative gender binaries. Thus, there is potential for error in the observed gender make-up of $23^{\text {rd }}$ Street cyclists, for those with non-traditional gender expressions or who do not identify with masculine or feminine genders.

It must be noted that major road construction began on Idylwyld Drive mid-study. This unanticipated event potentially skewed the traffic counts on the boulevard, especially for site one (at $23^{\text {rd }}$ Street and Avenue E), as cars were funneled into the city's west side. The construction lasted several weeks, and was therefore unavoidable once it began.

This study does not address how differences in cyclist routes could affect their perceptions of the boulevard. For example, a survey participant who only uses the boulevard for six specific blocks might lack awareness of the boulevard outside that area. It is unlikely that all survey participants have a comprehensive understanding of all thirty blocks of the boulevard. A later study might consider how differences in cycling routes affect user perceptions of the boulevard.

NACTO offers clear guidelines on how fast motor traffic should travel on a bike boulevard. Due to a lack of equipment, this study had no way of measuring this. A future study of the boulevard should measure traffic speeds to gain a better understanding of how the boulevard functions. Similarly, a more robust traffic count could better judge how well the boulevard is functioning compared with its counterparts across the continent.

Finally, it should be noted that the researcher and some survey participants observed several taxis using the boulevard. It is likely that this indicates that the bike boulevard is being used as a short cut for motor traffic, but this was not addressed. Examining the choice of taxi routes around the boulevard would likely provide enlightening results for a future study.

\section{Conclusions and Recommendations}

Demographic indicators suggest that Saskatoon's bicycle boulevard has had mixed success in creating effective bicycle infrastructure. This mixed success can be attributed to the mixed way that Saskatoon has embraced the basic elements of bicycle boulevard design (NACTO, 2012).

The city has been successful in creating a mostly safe and logical route, with abundant signage/pavement markings as well as a route where traffic speeds are relatively low when compared to other streets. However, the city has been less successful in controlling motor traffic volumes on the route and in dealing with how cyclists must navigate intersections involving motorists. Thus, there are safety concerns among boulevard users regarding areas where cyclists mix with motorists, and this is reflected in their suggestions for how the boulevard should be improved. The failure to address all of the components of bicycle boulevard design arises from contradictory understandings of how cyclists interact with motorists. One cannot prioritize cyclist traffic without placing some restrictions on motorized car traffic. This misunderstanding is also the greatest opportunity for boulevard improvement.

Saskatoon has made promising steps in the direction of inclusive transportation, but if the city wants to fully capitalize on the many benefits of urban cycling, it should improve the bicycle boulevard in a number of ways. Most importantly, the city must reduce the number of areas where cyclists must compete with motorists. This can be accomplished through increasing the number of motorist volume controls throughout the boulevard, redesigning key intersections to be safer for cyclists using NACTO (2012) standards, and redesigning existing traffic calming measures such that they are no longer obstacles for cyclists. Figure 6 indicates which areas of the boulevard should be prioritized for potential redesign, including the areas near Idylwyld Drive, at the choker and traffic circles, and at Avenue P. Additionally, the boulevard could be improved for many users by repaving problem areas. The city should also continue to address perceived or actual crime in the area of the boulevard, in order to ensure its success as a public space.

This study is a taste-tester, and is hopefully the first of many attempts to examine and improve the bicycle boulevard. This study represents the efforts of one student operating within the constraints of an undergraduate course requirement. There are many limitations in the methods and capabilities of the researcher that future studies could no doubt overcome. However, this study is the first to examine this new infrastructure and certainly will help to provide insight into the bicycle boulevard's effectiveness. This paper reminds us that there better ways to accommodate cyclists. Saskatoon should strive for the best possible cycling infrastructure, so that the safety and quality of life of its citizens can reach new heights. 


\section{Acknowledgements}

This project could not have happened without the guidance of Dr. Jill Gunn in the Department of Geography and Planning at the University of Saskatchewan. Her knowledge of field research techniques formed the basis of this report. Special thanks must also be extended to Sean Shaw of Saskatoon Cycles for introducing the author to the study site. 


\section{References}

Baker, L. (2009, October 16). How to get more bicyclists on the road. Scientific American Magazine. 16.

Retrieved from

http://www.scientificamerican.com/article/gettingmore-bicyclists-on-the-road/

City of Saskatoon. (2002). Comprehensive Bicycle Plan.

Retrieved from

https://www.saskatoon.ca/sites/default/files/docu ments/transportation-

utilities/transportation/cycling/plan/BikePlan2002. pdf

City of Saskatoon. (2011). Neighborhood Profiles. Retrieved November 12, 2013, from City of Saskatoon Web site:

https://www.saskatoon.ca/sites/default/files/neigh bourhood_profiles.pdf

City of Saskatoon. (2012). "Bike Boulevard" Frequently Asked Questions. Retrieved November 5, 2013, from City of Saskatoon Web site:

http://www.saskatoon.ca/DEPARTMENTS/Infrastr ucture\%20Services/Transportation/Cycling/Cycling LanesPathwaysAndTrails/Documents/Frequently\% 20Asked\%20Questions\%20-

\%2oBike\%2oBoulevard.pdf

Emond, C. R., Handy, S. L., \& Tang, W. (2009). Explaining gender difference in bicycling behavior. Journal of the Transportation Research Board, 2125, 16-25. doi: $10.3141 / 2125-03$

Fehr \& Peers. (2013). Traffic Calming Effectiveness. Retrieved November 5, 2013, from Traffic Calming Web site: http://trafficcalming.org/

Flusche, D. (2012). Bicycling means business: The economic benefits of bicycle infrastructure. Retrieved from Advocacy Advance website:

http://www.advocacyadvance.org/site_images/con tent/Final_Econ_Update(small).pdf

Gehl, J. (2010). Cities for People. Washington: Island Press.

Google Maps. (2013. [Saskatoon, Saskatchewan] [Street map]. Retrieved from

https://www.google.ca/maps/place/Saskatoon,+SK l@52.1458044,-

106.7582512,11.5z/data $=! 4 \mathrm{~m} 2 ! 3 \mathrm{~m} 1$ ! $150 \times 5304 \mathrm{f} 6 \mathrm{bf} 47$ edg92b:0x5049e329577269o
The Effectiveness of Saskatoon's Bicycle Boulevard (Surkan)

Hamilton, C. (2013, September 10). Cyclist dragged by vehicle dies in Saskatoon hospital. Saskatoon Star Phoenix, pp. A1.

Hutton, D. (2012, May 15). Saskatoon cycles says 23rd Street concept 'not a true bike boulevard'. Saskatoon Star Phoenix . Retrieved from http://thestarphoenix.com/news/localnews/saskatoon-cycles-says-23rd-street-conceptnot-a-true-bike-boulevard

Marshall, W. E., \& Garrick, N. W. (2011). Evidence on Why Bike-Friendly Cities are Safer for All Road Users. Environmental Practice, 13 (01), 16-27. doi: $10.1017 / \mathrm{s} 1466046610000566$

Minikel, E. (2012). Cyclist safety on bicycle boulevards and parallel arterial routes in Berkeley, California. Accident Analysis and Prevention (45), 241-247. doi: 10.1016/j.aap.2011.07.009

National Association of City Transportation Officials. (2012, September 4). Bicycle Boulevards. Retrieved November 3, 2013, from National Association of City Transportation Officials Web site: nacto.org/cities-for-cycling/design-guide/bicycleboulevards/

Orton, T. (2013, June 10). Safer options attract more female cyclists: Report. Retrieved from http://vancouver.24hrs.ca/2013/06/og/saferoptions-attract-more-female-cyclists

Pucher, J., \& Buehler, R. (2008). Cycling for everyone: Lessons from Europe. Journal of the Transportation Research Board, 2074, 58-65. doi: 10.3141/2074-08

Pucher, J., \& Renne, J. L. (2003). Socioeconomics of urban travel: Evidence from the 2001 NHTS.

Transportation Quarterly, 57 (3), 49-77. Retrieved from: http://www.vtpi.org/documents/evaluation.p hp

Statistics Canada. (2011). Commuting to Work: National Household Survey (NHS) (Catalogue No. 99-0122011003). Ottawa: Statistics Canada.

Statistics Canada. (2012). Focus on Geography Series, 2011 Census. (Catalogue No. 98-314-XWE2011004) Ottawa: Statistics Canada. 
Szczepanski, C. (2013). Women on a roll: Benchmarking women's bicycling in the United States - and five keys to get more women on wheels. Retrieved from League of American Bicyclists website:

http://bikeleague.org/sites/default/files/WomenBik eReport(web).pdf

VanZerr, M. (2009). Resident perceptions of bicycle boulevards: A Portland, Oregon case study. 8gth Annual Meeting of the Transportation Research Board. Symposium conducted at the 8gth Annual Meeting of the Transportation Research Board. Washington, D.C.

Walker, L., Tresidder, M., \& Birk, M. (2009). Fundamentals of Bicycle Boulevard Planning \& Design. Portland, OR: Initiative for Bicycle and Pedestrian Innovation, Center for Transportation Studies \& Center for Urban Studies, Portland State University. 
The Effectiveness of Saskatoon's Bicycle Boulevard (Surkan)

University of Saskatchewan Undergraduate Research Journal 